\title{
Stray bullet injuries in a tertiary care center
}

\author{
NICHOLAS BATLEY, RINAD BAKHTI, RANA BACHIR, AFIF MUFARRIJ \\ Department of Emergency Medicine, American University of Beirut Medical Center, Beirut, Lebanon
}

Corresponding author:

Afif Mufarrij

Department of Emergency Medicine

American University of Beirut Medical Center

P.O.Box - 11-0236 Riad El Solh

Beirut 11072020

Phone: +961-1-350000 Ext: 6636

E-mail:am66@aub.edu.lb

\section{ABSTRACT}

Background. A stray bullet injury is defined as an accidental firearm injury occurring outdoors by an anonymous attacker. Stray bullet injuries are rare, but not uncommon in certain parts of the world. In Pakistan, 165 patients with stray bullet injuries were recorded between 2006 and 2010.

Objectives. In Lebanon, gunshots may occur during politicians' speeches, funerals and after exam results are published. No studies to date have looked at the details and consequences of these gunshot injuries.

Methods. A retrospective chart review of patients presenting to an emergency department (ED) in Beirut, Lebanon, from 2010 to 2015 , with clear stray bullet injuries was conducted. Variables included: demographics, injured body part, admission to hospital, number of days in hospital, length of stay in the ED, mortality, past medical history, emergency severity index, and consequences of injury including surgery.

Results. Out of 154 bullet injuries, 12 stray bullet injuries were recorded. Injuries of the lower extremity were most common, followed by the head, shoulder/thorax, abdomen/pelvis and upper extremity. Surgery was needed in 7 patients $(58.3 \%)$. The median length of stay was 3.08 hours in the ED and 4.78 days in hospital. There were no recorded deaths. Consequences of each stray bullet injury are presented.

Conclusion. Stray bullet injuries are commonly reported on in news and media outlets. This is the first study in Lebanon and the region to document cases of stray bullet injuries presenting to the ED. Better laws and educational policies need to be implemented to help discourage this practice.

Key words: stray bullets, emergency department, injured body part, consequences of stray bullets, hospital admissions, severity of injury, surgical intervention, Lebanon

\section{INTRODUCTION}

A 38-year-old female presented to the Emergency Department (ED) at the American University of Beirut Medical Center (AUBMC). She was having dinner on the veranda of a seaside restaurant in Beirut when she developed a sudden, severe right-sided headache and bleeding from a scalp wound. The patient underwent a computed tomography (CT) scan of the brain, which revealed a bullet lodged in the scalp with no skull fracture or intracranial injury (figure 1). The bullet was removed without complication, the scalp was sutured and the patient discharged home in a stable condition.

The International Classification of Diseases defines a stray bullet injury as an accidental firearm injury occurring outdoors by an anonymous attacker. (1) Although stray bullet injuries are generally rare, they are not entirely uncommon in certain parts of the world. (2) Falling bullets may hit people, more commonly in populated areas like cities, cause injury and in some cases, result in death. (3) In a sample of 284 cases, $81 \%$ of those injured were unaware of the causes or events of the shooting. (4)

Generally, a bullet that is fired vertically will fall at its terminal or free fall velocity based on bullet characteristics like weight and shape, its kinetic energy, and whether it lands base or nose first. (5) The degree of tissue damage also varies based on the size of the organ or tissue and the resistance of the tissue to strain. (6) A bullet that hits 'nose first' will have the highest terminal velocity and might cause more damage. (5) This can occur from both handguns and rifles. With an AK47 rifle, the velocity of a bullet is 2,330 feet per second (fps) with a bullet weight of 7.9 grams, while an M16 has a velocity of 3,250 fps and a bullet weight of 3.6 grams. (7) The maximum range of an AK47 and an M16 is 2300 meters and 2700 meters, respectively. (8) Bullets with a caliber of 0.30 may have a terminal velocity of $300 \mathrm{fps}$, whereas larger bullets of 0.50 caliber may have a velocity of $500 \mathrm{fps}$. (9)

The trajectory of a bullet, called "horizontal projectile motion," will continue to accelerate when shot in the air until it arrives at a point where its weight is equal to the resistance of the air. Although when falling, these bullets are not at optimum velocity, they might still reach $600 \mathrm{fps}$ while falling down. A speed of $148 \mathrm{fps}$ is sufficient for a bullet to penetrate the skin whereas a bullet at $200 \mathrm{fps}$ can potentially pierce through bone structures and enter the skull. (10) When a bullet is shot at a high but non-vertical angle, it is more likely to be potentially fatal on return. (5) With most cases of stray bullet injuries, the bullet is stuck in subcutaneous regions with no exit wounds.

In Lebanon, gunshots are frequently heard during politicians' speeches, funerals and after exam results are published. (11) No studies to date have looked at the conse- 
quences of these gunshots. The purpose of the current work is to better define stray bullet-induced pathology and its consequences.

\section{MATERIALS AND METHODS}

The present paper summarizes the data on stray bullet injuries presenting to the ED of AUBMC in Beirut, Lebanon, from January 2010 to November 2015. The study was approved by the Institutional Review Board at AUBMC. AUBMC is the largest tertiary care center in Lebanon, receiving approximately 49,000 patient visits per year. The ED is divided into three levels: a high acuity section (ED1), low acuity section (ED2) and a pediatrics section (ED3). Triage is conducted according to the Emergency Severity Index (ESI) scoring system, assigning severity scores to patients. (12) ESI consists of five levels used to assess patient acuity from level 1 (most urgent) to level 5 (least resource intensive). During the study period, 288,361 patients were admitted to the ED. The ESI distribution of those seen was $0.4 \%, 7 \%, 67.7 \%, 22.7 \%$, and $2.2 \%$ for ESI 1, 2, 3, 4, and 5, respectively. Payment was covered though private insurance in $72.5 \%$ of cases, $25 \%$ out-of-pocket and $2.5 \%$ through governmental insurance.

A retrospective chart review of patients of all ages presenting to the ED in Beirut, Lebanon, in these five years with clear stray bullet injuries, was conducted. Stray bullet cases were defined as unintentional injuries resulting from an unknown shooter. The diagnoses are categorized as per the International Classification of Diseases, Ninth Revision, Clinical Modification (ICD-9$\mathrm{CM}$ ), which assigns numeric codes to diagnoses. Exclusion criteria included any bullet injuries that were not explicitly listed as stray bullets by the attending physician in the ED at the time of injury.

Data were extracted on: injured body part, admission to hospital, number of days spent in hospital, length of stay in the ED, mortality, past medical history, ESI and consequences of injury, including whether or not surgery was required. Additionally, demographic variables such as age, gender, marital status and type of insurance were collected.
Statistical analyses were carried out using SPSS 23 (Statistical Package for Social Sciences). In the univariate analyses, descriptive statistics and frequency distributions were presented whereas the continuous variables were analyzed as means, standard deviations, ranges and percentiles.

\section{RESULTS}

Out of a total of 154 bullet injuries, 12 cases were found to be stray bullet injuries. Socio-demographic and clinical characteristics are presented in table 1 (Appendix A). The sample was composed of 5 males $(41.7 \%)$ and 7 females (58.3\%), with a median age of 25.5 years. Four were married $(33.3 \%)$ and the remaining were single $(66.7 \%)$. A total of 7 were self-paying patients $(58.3 \%)$. Five patients $(55.6 \%)$ had received an ESI of 2 while four (44.4\%) had an ESI of 3 at triage. Only two reported having any past medical history (16.7\%). Almost all patients were admitted to the hospital except for one (91.7\%). Injuries of the lower extremity were most common with 5 cases $(41.7 \%)$, followed by the head with 3 cases (25\%), shoulder/thorax, 2 cases (16.7\%), one case of abdominal/ pelvic injury $(8.3 \%)$ and one case of an injured upper extremity (8.3\%). Surgery was required for 7 patients $(58.3 \%)$. The median length of stay during their visit was found to be 3.08 hours in the ED and 4.78 days in the hospital. There were no recorded deaths. Each case, along with the consequences of injury, is presented in Appendix B.

\section{DISCUSSION}

In the US, between 2008 and 2009, 317 people were injured by stray bullets, 65 of whom died. (4) In Los Angeles specifically, 118 cases of stray bullet injuries were recorded across a 7 year period, with $77 \%$ resulting in an injury to the head, $12 \%$ to the shoulder, $5 \%$ to the upper back, $2 \%$ to the posterior chest and neck and $1 \%$ to the upper arm, leg, and foot each, with a mortality rate of $32 \%$. (13) In cases where the source of the bullet was known, all were found to be fired by handguns from within a one mile radius. A high mortality rate was found for those hit in the head (40\%) and posterior chest (50\%). Of the $2 \%$ of bullets hitting the chest, only a fraction had injured the heart. Some consequences included seizures, neurologic deficits and joint immobility.

Between 2006 and 2010, 165 patients with stray bullet injuries were detected in the Sind province of Pakistan. (14) The majority $(61.8 \%)$ presented with peritonitis, followed by haemothorax/ pneumothorax in $11 \%$ of cases. Additionally, 55\% underwent laparotomy, whereas the rest had chest tubes inserted and other procedures done. In terms of consequences of injury, nine people suffered permanent disabilities and 13 died. In a similar study from Pakistan, 144 injuries from stray bullets were assessed; marriage ceremony celebrations were the most common cause. (3) Of the 144 cases, 102 were considered a trivial injury, while the rest required surgical intervention. The mean hospital stay was 13 days and the surgical interventions conducted were: chest intubation, wound tract exploration to retrieve the bullet, and laparotomy to manage intra-abdominal injury, with no recorded deaths.

According to the Centers for Disease Control and Prevention, 2 people die and 25 people are injured annually on New Year's Eve in Puerto Rico. (15) The most common site of injury is the head (36\%), followed by the foot (26\%) and then shoulder (16\%).

In some countries in the Middle East, gunfire often occurs during weddings, graduations, (2) political speeches and clashes. (11) There are, however, few academic studies or case reports on the topic. In Libya, 23 cases of stray bullet injuries were reported between 2011 to 2012, with 2 recorded deaths. The upper and lower limbs were the most common injured body part followed by the chest and head/neck. (2)

In the present study, the most common site of injury was the extremities, including calf, thigh, and leg. This is in line with the epidemiology of stray bullet injuries found across the US,(4) revealing that in a sample of 284 cases, extremities were the most injured body part, and similarly for the Libyan sample.(2) In samples where the chest (3) and the head (11) were most commonly injured, a much higher mor- 
tality ratewas recorded. As with the Los Angeles sample, perforating injuries were rare. (11) Resulting admission to the hospital for further management, number of days spent in hospital and surgical intervention for the Libyan sample was also at a similar rate as the present sample. (2)

This is a single-center, retrospective study with a low sample size. There are a total of 164 hospitals in Lebanon. (16) As such, the total number of stray bullet injuries in Lebanon is projected to be much higher.

\section{CONCLUSION}

Although cases of stray bullet injuries are reported in news and media outlets, academic articles and case reports are comparatively few. This is the first study in Lebanon to document cases of stray bullet injuries presenting to an ED. The act is considered illegal and the government has previously warned against it. The majority of people believe, however, that bullets shot in the sky vanish or disappear into space.
(3) Laws, educational policies and campaigns to inform the population should be better implemented to avoid such injuries and reduce the significant threat to public health that stray bullets represent. This study aims to highlight the dangers of this practice with the aim of encouraging its prevention and limiting resulting injuries.

\section{REFERENCES}

1. World Health Organization. International statistical classification of diseases and related health problems. World Health Organization; 2004.

2. Al-Tarshihi MI, Al-Basheer M. The falling bullets: post-Libyan revolution celebratory stray bullet injuries. Eur J Trauma Emerg Surg $2014 \mathrm{Feb} ; 40(1): 83-5$.

3. Ali SA, Tahir SM, Makhdoom A, Shaikh AR, Siddique AJ. Aerial firing and stray bullet injuries: a rising tide. Iran Red Crescent Med J 2015;17(4):26179.

4. Wintemute GJ, Claire BE, McHenry VS, Wright MA. Epidemiology and clinical aspects of stray bullet shootings in the United States. J Trauma Acute Care Surg 2012 Jul;73(1):215-23.

5. Haag L. Shooting incident reconstruction. Academic press; 2006.

6. Maiden N. Ballistics reviews: mechanisms of bullet wound trauma. Forensic Sci Med Pathol 2009;5(3):204-9.

7. Hartink AE. The complete encyclopedia of automatic army rifles. Hackberry Press; 2001. p. 119-20.

8. Kjellgren GLM. The Practical Range of Small Arms. The American Rifleman; 1970.

9. Shuker ST, Sadda R. Craniomaxillofacial falling bullet injuries and management. J Oral Maxillofac Surg 2010 Jul;68(7):1593-601.

10. Ordog GJ, Wasserberger J, Balasubramanium S. Wound ballistics: theory and practice. Ann Emerg Med 1984 Dec;13(12):1113-22.

11. El Hassan, J. Stray bullets are no cause for celebration [Online]. 2013 Sep 5. Available from: URL:http://www.dailystar.com.lb

12. Eitel DR, Travers DA, Rosenau AM, Gilboy N, Wuerz RC. The emergency severity index triage algorithm version 2 is reliable and valid. Acad Emerg Med 2003 Oct;10(10):1070-80.

13. Ordog GJ, Dornhoffer P, Ackroyd G, Wasserberger J, Bishop M, Shoemaker W, et al. Spent bullets and their injuries: the result of firing weapons into the sky. J Trauma 1994 Dec;37(6):1003-6.

14. Malik AM, Alkadi A, Talpur KA, Qureshi JN. The incidence, pattern and outcome of stray bullet injuries. A growing challenge for surgeons. Pak J Med Sci 2013 Sep;29(5):1178-81.

15. Centers for Disease Control and Prevention. New Year's Eve injuries caused by celebratory gunfire-Puerto Rico, 2003. Morb Mortal Wkly Rep 2004;53:1174-5.

16. National Health Statistics Report in Lebanon [Online]. 2012. Available from: URL:http://www.igsps.usj.edu.lb/docs/recherche/recueil12en.pdf

\section{APPENDIX A}

Table 1. Descriptives.

\begin{tabular}{llllll}
\hline Variable & Median & Range & 25\% percentile & $\mathbf{5 0 \%}$ percentile & 75\% percentile \\
\hline Age & 25.50 & $11-58$ & 16.5 & 25.5 & 35 \\
$\begin{array}{l}\text { Length of stay in the } \\
\text { ED }\end{array}$ & 3.08 & $0.98-6.72$ & 1.75 & 3.08 & 4.25 \\
\hline $\begin{array}{l}\text { Length of stay in the } \\
\text { hospital }\end{array}$ & 4.78 & $1-26.62$ & 3.08 & 4.78 & 7.08 \\
\hline
\end{tabular}

ED, emergency department. 
Table 2. Frequencies.

\begin{tabular}{|c|c|c|}
\hline Variable & Frequency & Percent \\
\hline \multicolumn{3}{|l|}{ Gender } \\
\hline Male & 5 & $41.7 \%$ \\
\hline Female & 7 & $58.3 \%$ \\
\hline \multicolumn{3}{|l|}{ Marital status } \\
\hline Single & 8 & $66.7 \%$ \\
\hline Married & 4 & $33.3 \%$ \\
\hline \multicolumn{3}{|l|}{ Payment } \\
\hline Insurance company & 5 & $41.7 \%$ \\
\hline Self-payer & 7 & $58.3 \%$ \\
\hline \multicolumn{3}{|l|}{ ESI } \\
\hline 2 & 5 & $55.6 \%$ \\
\hline 3 & 4 & $44.4 \%$ \\
\hline \multicolumn{3}{|l|}{ Past medical history } \\
\hline No & 10 & $83.3 \%$ \\
\hline Yes & 2 & $16.7 \%$ \\
\hline \multicolumn{3}{|c|}{ Admitted to the hospital } \\
\hline No & 1 & $8.3 \%$ \\
\hline Yes & 11 & $91.7 \%$ \\
\hline \multicolumn{3}{|l|}{ Injured body part } \\
\hline Lower extremity & 5 & $41.7 \%$ \\
\hline Shoulder/Thorax & 2 & $16.7 \%$ \\
\hline Upper extremity & 1 & $8.3 \%$ \\
\hline Head & 3 & $25.0 \%$ \\
\hline Abdomen/Pelvis & 1 & $8.3 \%$ \\
\hline \multicolumn{3}{|l|}{ Surgery } \\
\hline No & 5 & $41.7 \%$ \\
\hline Yes & 7 & $58.3 \%$ \\
\hline
\end{tabular}

\section{APPENDIX B}

Table 3. Stray bullet injuries.

\begin{tabular}{|c|c|c|c|c|c|c|c|}
\hline Age & Gender & Injured body part & $\begin{array}{l}\text { Classification of } \\
\text { Injury }\end{array}$ & $\begin{array}{l}\text { Admitted to } \\
\text { hospital }\end{array}$ & $\begin{array}{l}\text { Days in } \\
\text { hospital }\end{array}$ & Consequences of injury & Surgery \\
\hline 24 & Female & Right leg & Lower extremity & Yes & 7 & Open fracture of distal tibia fibula & Yes \\
\hline 16 & Male & $\begin{array}{l}\text { Left shoulder, left poste- } \\
\text { rior thoracic wall, bullet } \\
\text { projecting over first left } \\
\text { rib (did not enter chest } \\
\text { cavity). }\end{array}$ & Shoulder/Thorax & Yes & 1 & $\begin{array}{l}\text { No bleeding, no loss of conscious- } \\
\text { ness, no weakness, no paresthesia, } \\
\text { no exit site, no evidence of major } \\
\text { vascular injuries }\end{array}$ & No \\
\hline 28 & Female & Right thigh & Lower extremity & No & 0 & Right thigh superficial abrasion & No \\
\hline 58 & Female & $\begin{array}{l}\text { Left arm, bullet in } \\
\text { palmar aspect of forearm } \\
\text { (middle third and } \\
\text { distal third of posterior } \\
\text { forearm). }\end{array}$ & Upper extremity & Yes & 2 & $\begin{array}{l}\text { Bullet in the palmar aspect of the } \\
\text { forearm with associated overlying } \\
\text { soft tissue swelling }\end{array}$ & Yes \\
\hline 11 & Male & Left eye & Head & Yes & 2 & $\begin{array}{l}\text { Shrapnel injury leading to eye } \\
\text { redness, headache, and blurry } \\
\text { vision. Abrasion at limbus, corneal } \\
\text { laceration } 6 \mathrm{~mm} \text {. }\end{array}$ & No \\
\hline
\end{tabular}




\begin{tabular}{|c|c|c|c|c|c|c|c|}
\hline 36 & Male & Left mid-thigh & Lower extremity & Yes & 1 & Exploration and removal of bullet & No \\
\hline 32 & Male & $\begin{array}{l}\text { Left side of pelvis (ante- } \\
\text { rior entry through right } \\
\text { thigh). }\end{array}$ & Abdomen/Pelvis & Yes & 1 & Exploration and removal of bullet & Yes \\
\hline 37 & Female & Left shoulder & Shoulder/Thorax & Yes & 4 & $\begin{array}{l}\text { Apical pneumothorax, hemo- } \\
\text { thorax, bullet lodged in left lung. } \\
\text { Comminuted minimally displaced } \\
\text { fracture involving the left clavicle. } \\
\text { Required thoracotomy, removal of } \\
\text { bullet, bilateral chest tubes. }\end{array}$ & Yes \\
\hline 27 & Male & Frontal lobe of brain & Head & Yes & 2 & $\begin{array}{l}\text { Left craniotomy for removal of } \\
\text { bullet }\end{array}$ & Yes \\
\hline 20 & Male & $\begin{array}{l}\text { Face, eyes, and neck ( } 5 \\
\text { shrapnels to face). }\end{array}$ & Head & Yes & 23 & $\begin{array}{l}\text { Scleral repair of laceration, pars } \\
\text { plana vitrectomy }\end{array}$ & Yes \\
\hline 18 & Female & Left thigh & Lower extremity & Yes & 1 & $\begin{array}{l}\text { Fracture of the anterior cortex of } \\
\text { the left femur }\end{array}$ & Yes \\
\hline 11 & Male & Right calf & Lower extremity & Yes & 1 & $\begin{array}{l}\text { Mild swelling, soft tissue injury, no } \\
\text { bleeding, slight oozing }\end{array}$ & \\
\hline
\end{tabular}

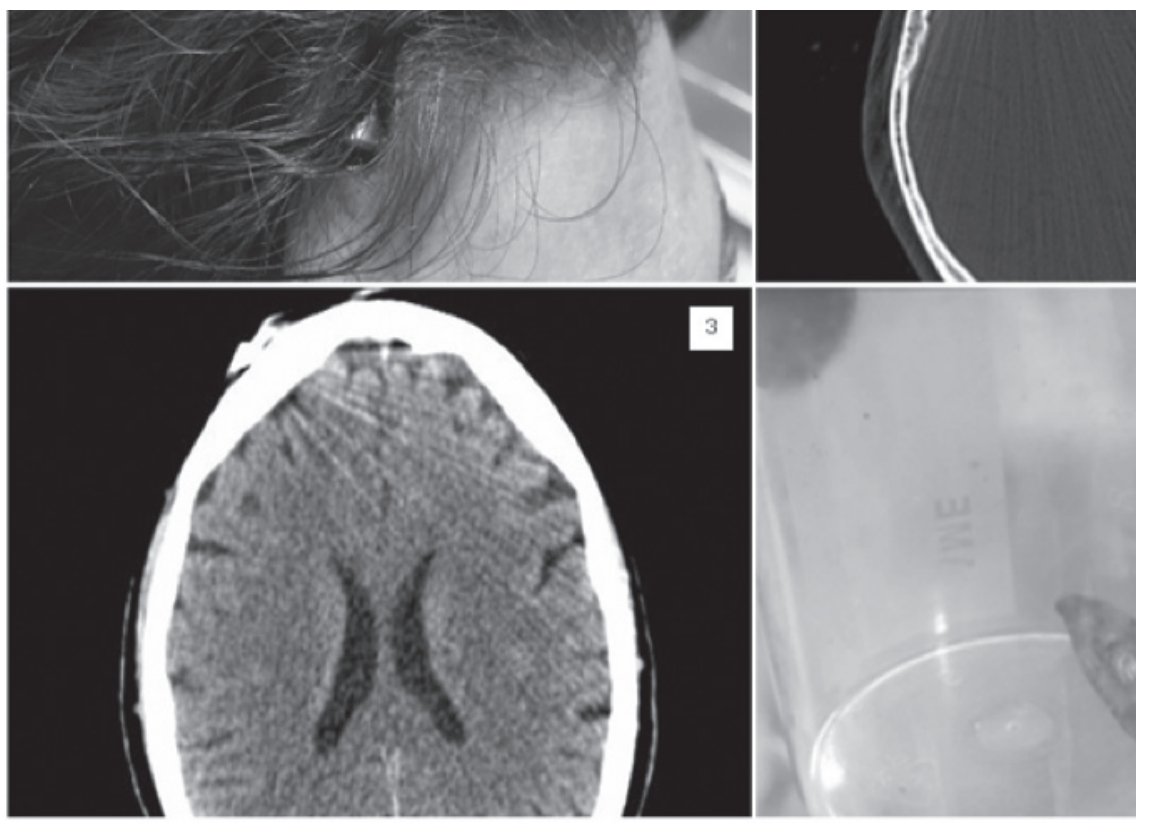

Figure 1. Stray bullet lodged in right side of head (1), computed tomography (CT) scan with bullet (2), CT scan after bullet removal (3), image of bullet (4). 